\title{
Editorial: Microbial Ecology in the North Pacific Subtropical Gyre
}

\author{
Samuel T. Wilson ${ }^{1 *}$ and Matthew J. Church ${ }^{2}$ \\ ${ }^{1}$ Department of Oceanography, Daniel K. Inouye Center for Microbial Oceanography: Research and Education, University of \\ Hawaii at Manoa, Honolulu, HI, United States, ${ }^{2}$ Flathead Lake Biological Station, University of Montana, Polson, MT, \\ United States
}

Keywords: microbial ecology, microbiology, North Pacific Subtropical Gyre, oligotrophic, biogeochemical cycling, bacteria, oceanography

\section{Editorial on the Research Topic}

\section{Microbial Ecology in the North Pacific Subtropical Gyre}

Microorganisms play a critical role in controlling the source-sink behavior and cycling of major and minor elements in the biosphere. This occurs through cellular metabolic processes such as photosynthesis, respiration, oxidation-reduction, assimilation, and exudation, and via interactions with other constituents of the food web including predation and viral lysis. In the open ocean, microbes influence key processes such as the uptake of carbon dioxide from the atmosphere and the export of carbon from the sunlit waters to the seafloor. The subtropical ocean gyres are large expansive ecosystems that play globally important roles in carbon cycling (Martin et al., 1987; Emerson et al., 1997). Our knowledge of these habitats was transformed through initiation of shipboard time-series programs in the late 1980s in both the Sargasso Sea and the North Pacific Subtropical Gyre (NPSG). In the NPSG, Station ALOHA was established as the field outpost for the Hawaii Ocean Time-series (HOT) program (Figure 1). After 30 years of near-monthly measurements at Station ALOHA, the seasonal and interannual variability associated with key ecosystem processes are now well-described (Figure 2). However, assessment of the contributions of specific microorganisms to the ecology and metabolic activity of the NPSG ecosystem remain less understood. Since recognition of the key role that the microbial food web plays in nutrient recycling and the flux of organic matter (Azam et al., 1983), numerous studies have highlighted the need to link the identity of specific microorganisms to cellular-level processes for insight into ecosystem-scale dynamics (e.g., Follows et al., 2007).

This Research Topic invited contributions on all aspects of microbial ecology in the NPSG. Consistent with the oligotrophic nature of this habitat, the majority of publications focus on light and nutrient acquisition by key groups of microbial populations. For example, van den Engh et al. examine the vertical depth distribution of Prochlorococcus and Synechococcus and show how these two groups of cyanobacteria are distributed in the lower euphotic zone. Casey et al. investigate how sunlight influences the metabolism of microorganisms in this ecosystem. Using glycolate as the experimental carbon compound, the authors quantify rates of photoheterotrophic metabolism. Two of the articles in this issue focus specifically on the ecology of nitrogen-fixing microorganisms in the NPSG. In particular, White et al. quantify the abundance of large nitrogenfixing microorganisms ("diazotrophs") over a 2 year period in the NPSG from both direct cell counts and quantitative polymerase chain reaction amplification of nitrogenase (nifH) genes. Turk-Kubo et al. provide measurements of microzooplankton grazing on diazotrophs in the near surface ocean. Their work helps constrains grazing of diazotrophs as a loss mechanism balancing growth of these microorganisms. This is a key term required for the improvement of representation 


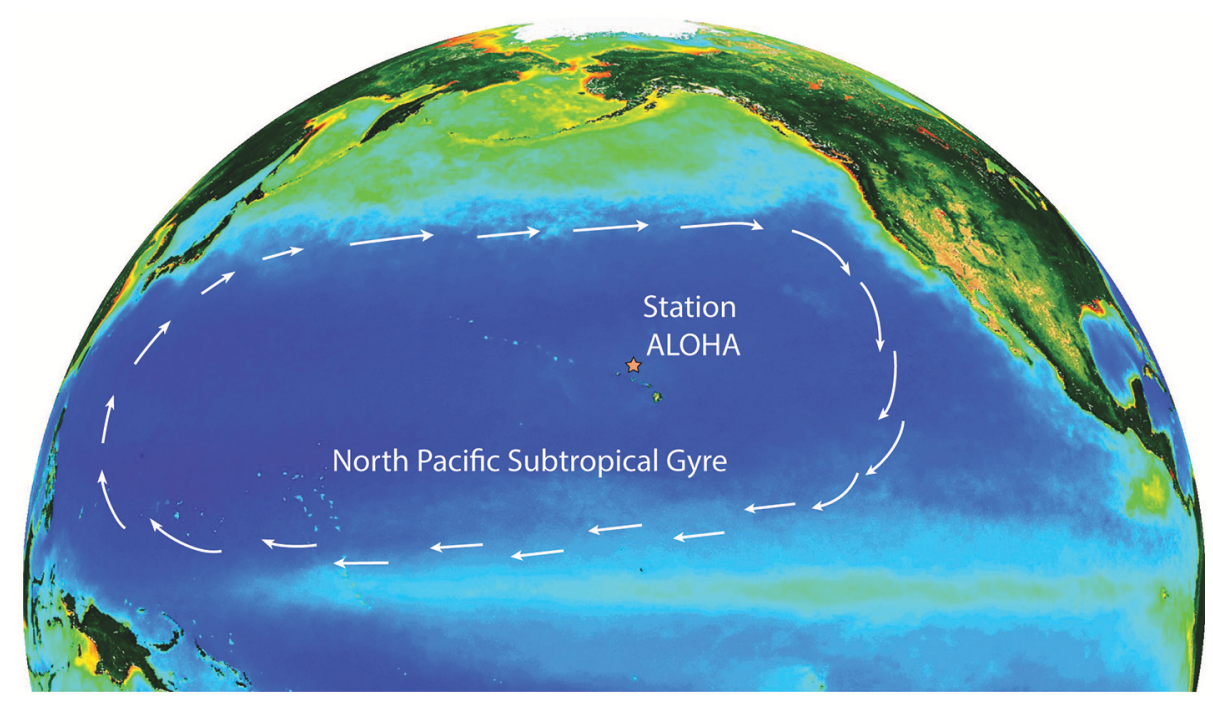

FIGURE 1 | Map of the North Pacific Ocean showing the North Pacific Subtropical Gyre and the location of Station ALOHA. The arrows depict the areal extent of the North Pacific Subtropical Gyre and show the direction of geostrophic flow. The background colors depict summer chlorophyll a distributions as determined by the SeaWiFS satellite mission (https://oceancolor.gsfc.nasa.gov/SeaWiFS/).

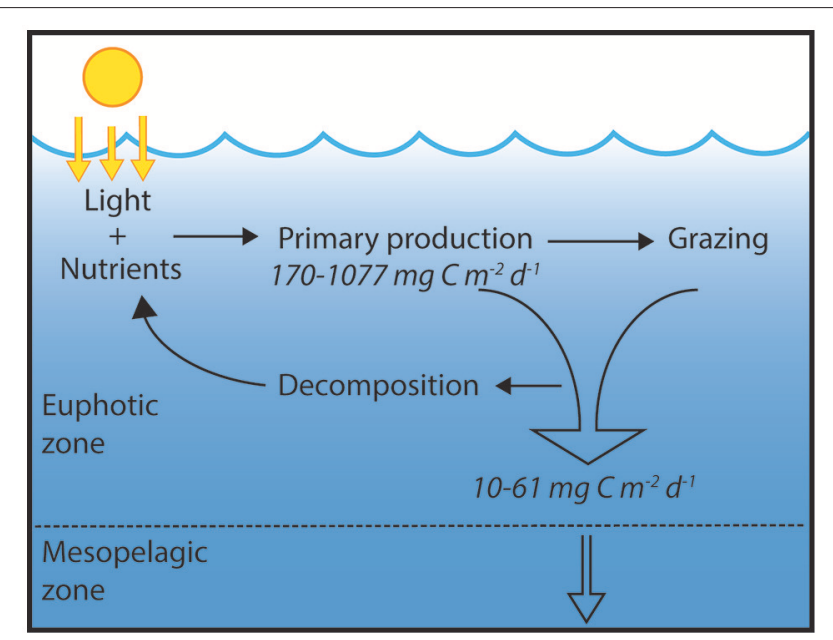

FIGURE 2 | Schematic of ecosystem process in the upper ocean, highlighting the central roles of primary production, grazing, remineralization, and export. The microorganisms and metabolic activity that regulates these fluxes form the basis of this Research Topic. The values depicted represent the range of carbon input via primary production (as measured by ${ }^{14} \mathrm{C}$ assimilation) and carbon export via sinking particles (as measured by particle interceptor traps); all data were obtained from the Hawaii Ocean Time-series program (http:// hahana.soest.hawaii.edu/hot/hot-dogs/interface.html).

of diazotrophs in ecosystems models (Monteiro et al., 2010). Other papers in this issue evaluate how specific nutrient substrates influence the growth of microorganisms. Rii et al. investigate the response of naturally-occurring photosynthetic picoeukaryotes and larger $(>3 \mu \mathrm{m})$ phytoplankton to both nitrate and ammonium. These authors identify that phylogenetically distinct groups of phytoplankton demonstrate seasonally-dependent responses to nitrogen availability.
Sosa et al. highlight microbial acquisition of carbon and phosphorus from high molecular weight dissolved organic material. Their observations link widespread members of the bacterioplankton, including members of the Roseobacter and Gammaproteobacteria, to semi-labile dissolved organic material cycling and aerobic production of methane in the ocean. Bundy et al. examined acquisition of dissolved iron by marine microorganisms, identifying, and quantifying vertical distributions of iron-binding siderophores in the NPSG. Their results demonstrate that the vast majority of iron in this ecosystem is organically complexed, and highlight a possible role for complexed iron in regulating microbial utilization of organic matter in this ecosystem. Pelve et al. utilized metagenomics to characterize microbial communities associated with sinking particles. Through the use of preserved (i.e., poisoned) and non-preserved collection of sinking particles, they identify successional patterns in microorganisms that facilitate the degradation of particles as they sink from the upper ocean to the deep sea. Finally, Kavanaugh et al. leverage satellite remote sensing observations to assess how interannual variability in the spatial extent of the oligotrophic NPSG influences the time series observations at Station ALOHA. The resulting analyses provide new insights into how gyre-scale spatial heterogeneity influences the fixed point observations conducted at Station ALOHA.

In summary, the papers included in this Research Topic focused on novel aspects of the ecology and biogeochemical role of microorganisms in the NPSG, with particular focus on linking the identities and functions of microorganisms to ecosystem-scale patterns. These contributions provide new information on ecological interactions occurring among the microbial community of the NPSG, ultimately helping to resolve key aspects of ocean ecosystems necessary for improving predictive models on the role of ocean biology on Earth's climate system. 


\section{AUTHOR CONTRIBUTIONS}

All authors listed have made a substantial, direct and intellectual contribution to the work and approved it for publication.

\section{ACKNOWLEDGMENTS}

Papers featured in this Special Issue leveraged the field data and/or scientific infrastructure of the Hawaii Ocean Time-series

\section{REFERENCES}

Azam, F., Fenchel, T., Field, J. G., Gray, J. S., Meyer-Reil, L. A., and Thingstad, F. (1983). The ecological role of water-column microbes in the sea. Mar. Ecol. Prog. Ser. 10, 257-263. doi: 10.3354/meps010257

Emerson, S., Quay, P., Karl, D., Winn, C., Tupas, L., and Landry, M. (1997). Experimental determination of the organic carbon flux from open-ocean surface waters. Nature 389, 951-954. doi: 10.1038/40111

Follows, M. J., Dutkiewicz, S., Grant, S., and Chisholm, S. W. (2007). Emergent biogeography of microbial communities in a model ocean. Science 315, 1843-1846. doi: 10.1126/science.1138544

Martin, J. H., Knauer, G. A., Karl, D. M., and Broenkow, W. W. (1987). VERTEX: carbon cycling in the northeast Pacific. Deep Sea Res. 34, 267-285. doi: 10.1016/0198-0149(87)90086-0
(HOT) program, the Center for Microbial Oceanography: Research and Education (C-MORE), and the Simons Collaboration on Ocean Processes and Ecology (SCOPE). Together, these programs have increased our understanding of the interconnections between microbial ecology and biogeochemical cycling in the NPSG. The U.S. National Science Foundation provided funding for both HOT and C-MORE (awards OCE-1260164 and EF-0424599, respectively), while the Simons Foundation funds the SCOPE program (award \#329108).

Monteiro, F. M., Follows, M. J. and Dutkiewicz, S. (2010). Distribution of diverse nitrogen fixers in the global ocean. Global Biogeochem. Cycles 24:GB3017. doi: 10.1029/2009GB003731

Conflict of Interest Statement: The authors declare that the research was conducted in the absence of any commercial or financial relationships that could be construed as a potential conflict of interest.

Copyright (C) 2018 Wilson and Church. This is an open-access article distributed under the terms of the Creative Commons Attribution License (CC BY). The use, distribution or reproduction in other forums is permitted, provided the original author(s) and the copyright owner(s) are credited and that the original publication in this journal is cited, in accordance with accepted academic practice. No use, distribution or reproduction is permitted which does not comply with these terms. 